\title{
Prognostic value of PDL1 expression in pancreatic cancer
}

\author{
David J. Birnbaum ${ }^{1,2,3}$, Pascal Finetti ${ }^{1}$, Alexia Lopresti ${ }^{1}$, Marine Gilabert ${ }^{4,5}$, Flora \\ Poizat $^{4,7}$, Olivier Turrini ${ }^{3,4,6}$, Jean-Luc Raoul ${ }^{4,5}$, Jean-Robert Delpero ${ }^{3,4,6}$, Vincent \\ Moutardier $^{2}$, Daniel Birnbaum ${ }^{1,3}$, Emilie Mamessier ${ }^{1,4, *}$ and François Bertucci ${ }^{1,3,4,5, *}$ \\ ${ }^{1}$ Département d'Oncologie Moléculaire, Centre de Recherche en Cancérologie de Marseille, INSERM, CNRS, Université Aix- \\ Marseille, Marseille, France \\ 2 Département de Chirurgie Générale et Viscérale, AP-HM, Marseille, France \\ 3 Faculté de Médecine, Aix-Marseille Université, Marseille, France \\ ${ }^{4}$ Equipe de Médecine Translationelle Hépato-gastro-entérologie, Institut Paoli-Calmettes, Marseille, France \\ ${ }^{5}$ Département d'Oncologie Médicale, Institut Paoli-Calmettes, Marseille, France \\ ${ }^{6}$ Département d'Oncologie Chirurgicale, Institut Paoli-Calmettes, Marseille, France \\ 7 Département d'Anatomopathologie, Institut Paoli-Calmettes, Marseille, France \\ * These authors have equally contributed to this work \\ Correspondence to: François Bertucci, email: bertuccif@ipc.unicancer.fr \\ Keywords: expression, immune response, pancreatic cancer, PDL1, survival \\ Received: May 10, $2016 \quad$ Accepted: August 24, $2016 \quad$ Published: August 29, 2016
}

\section{ABSTRACT}

Pancreatic cancer is one of the most aggressive human cancers. PD1/PDL1inhibitors recently showed promising results in different cancers with correlation between PDL1 tumor expression and responses. Expression of programmed cell death receptor ligand 1 (PDL1) has been scarcely studied in pancreatic cancer. In this retrospective study, we analyzed PDL1 mRNA expression in 453 clinical pancreatic cancer samples profiled using DNA microarrays and RNASeq. Compared to normal pancreatic samples, PDL1 expression was upregulated in $19 \%$ of cancer samples. Upregulation was not associated with clinicopathological features such as patients' age and sex, pathological type, tumor size, lymph node status, and grade, but was associated with shorter disease-free survival and overall survival in multivariate analyses. Analysis of correlations with biological parameters showed that PDL1 upregulation was associated with some degree of lymphocyte infiltration and signs of anti-tumor T-cell response, but to a lesser extent than what has been reported in breast cancer and GIST. PDL1-up pancreatic cancers displayed profiles of lymphocyte exhaustion, were more enriched in inhibitory molecules and pro-tumor populations (Tregs with upregulation of FOXP3 and IL10, myeloid-derived suppressor cells with upregulation of $C D 33$ and $S 100 A 8 / A 9)$, and demonstrated a down-modulation of most MHC class I members $(H L A-A / B / C, H L A-E / F / G)$ suggestive of a defect in antigen processing and presentation. In conclusion, our results suggest that PDL1 expression might refine the prediction of metastatic relapse in operated pancreatic cancer, and that PD1/PDL1 inhibitors might reactivate inhibited T-cells to increase the anti-tumor immune response in PDL1-upregulated tumors.

\section{INTRODUCTION}

Pancreatic ductal adenocarcinoma is a major public health problem worldwide with 260,000 deaths annually [1] and its incidence is rising [2]. Early radical resection of the tumor is the only potentially curative treatment, but at diagnosis less than $20 \%$ of patients are eligible for surgery. The inoperability and the poor prognosis are due to late diagnosis, propensity to rapid dissemination to lymph nodes and distant organs $(>80 \%$ of patients displayed metastases at diagnosis) [3], early recurrences after resection, and poor response to available systemic therapies $[4,5]$. The median survival in patients with inoperable or metastatic pancreatic cancer is of 6 months 
from diagnosis and the long-term survival is null. During the past 20 years, research efforts have mainly focused on improvements in radiotherapy and systemic treatments. Today, there are only few chemotherapeutic agents that have shown to be effective against pancreatic carcinoma, including gemcitabine with or without nab-paclitaxel as well as the FOLFIRINOX regimen that combines 5-FU, leucovorin, oxaliplatin and irinotecan. Unfortunately, the survival benefit remains modest, making crucial the development of novel drugs. The success of immunotherapy in other cancers and various evidences for the role of immunity in pancreatic carcinoma [6-11] have suggested that immunotherapy can be a promising alternative in pancreatic cancer. One strategy is the development of immune checkpoint inhibitors that are changing the current treatment paradigm for cancers.

Immune response is balanced between activator and inhibitor pathways that regulate the activity of tumorinfiltrating lymphocytes (TILs). This balance may be disturbed in cancers, where the inhibition of the immune system favors tumor progression. The PD1 pathway plays a major role in the negative regulation of cell-mediated immune responses. PD1 (Programmed cell Death 1) is expressed at the surface of various immune cells including T-cells. PD1 is activated by its ligands, PDL1 or PDL2, expressed by antigen-presenting cells such as macrophages or B-cells but also by cancer cells. The PDL1-PD1 interaction attenuates lymphocyte activation [12-16], promotes regulatory T-cell development and function, and impairs anti-tumor T-cell immune response. PD1 or PDL1 inhibitors have shown very promising results in clinical trials notably in melanoma and renal, lung, prostate and bladder carcinomas [17-19], with durable tumor responses or stabilizations. In some cases, a relationship has been reported between therapeutic response and PDL1 expression on tumor and/or immune cells [17, 18, 20-22].

PDL1 expression has been described in different cancers such as breast, kidney, lung, esophagus, ovary, colorectal, head and neck and squamous cell carcinomas, melanomas, GIST and gliomas [23-36]. In pancreatic cancer, PDL1 expression has been very scarcely studied [27, 37-41], with the largest study analyzing 81 cases using immunohistochemistry (IHC). Here, we have analyzed PDL1 mRNA expression in 453 clinical pancreatic cancer samples profiled using DNA microarrays and RNASeq. We searched for correlations between PDL1 expression and clinico-pathological data, including survival.

\section{RESULTS}

\section{PDL1 expression and clinicopathological features}

We analyzed $P D L 1 \mathrm{mRNA}$ expression in 453 clinical pancreatic cancer samples pooled from nine data sets. Their clinicopathological characteristics are summarized in Supplementary Table 1. Ninety-nine percent of cases were ductal carcinoma and all but one had been initially treated by surgery. $P D L 1$ expression was variable among the 453 samples with a wide range of values over 3 decades in $\log _{2}$ scale, suggesting heterogeneous expression across samples (Supplementary Figure 1). We searched for correlations between PDL1 mRNA expression assessed as binary variable and available clinicopathological features. We thus defined two groups of cancer samples based upon $P D L 1$ expression in tumors compared with mean expression in normal pancreatic samples: the " $P D L 1$-up" group $(N=87 ; 19 \%)$ and the "PDL1-not-up" group $(N=$ $366,81 \%$ ). As shown in Table 1, the PDL1 groups were not associated with patient's age and sex, and pathological features such as pathological type, tumor size, lymph node status and tumor grade.

Finally, a recent study published a transcriptional classification of pancreatic ductal carcinoma identifying four tumor subtypes (squamous, pancreatic progenitor; immunogenic; and aberrantly differentiated endocrine exocrine) with different molecular pathways and prognosis [42]. We applied this classification to our dataset and found a significant correlation with the PDL1 status: $56 \%$ of PDL1-up tumors were in the squamous subtype (Table 1), the one with the worst prognosis. This was confirmed by the fact that PDL1 mRNA was up-regulated in the squamous subtype vs other subtypes in the Bailey's data set [42] and in our own data set (data not shown).

\section{PDL1 expression and survival}

We assessed the prognostic value of PDL1 expression in terms of disease-free survival (DFS) and overall survival (OS). DFS and OS data were available for 254 patients non-metastatic at diagnosis and treated with surgery. Regarding DFS, the median follow-up was 7.5 months (range, 1-84) months, 163 patients displayed a DFS event, and the 2-year DFS was $32 \%$ (95\%CI, 26-40). As shown in Figure 1, PDL1 expression influenced DFS with 14\% 2-year DFS (95\%CI, 7-31) in the "PDL1-up" group versus 37\% (95\%CI, 3-46) in the "PDL1-not-up" group ( $p=0.00032$, log-rank test). The HR for DFS event was $1.90(95 \% \mathrm{CI}, 1.33-2.70)$ in the "PDL1-up" group versus "PDL1-not-up" group ( $p=0.0004$, Wald test). The median DFS was 6 months (range, 1 to 63) in "PDL1-up" group versus 10.7 months (range, 1 to 156 ) in "PDL1- 


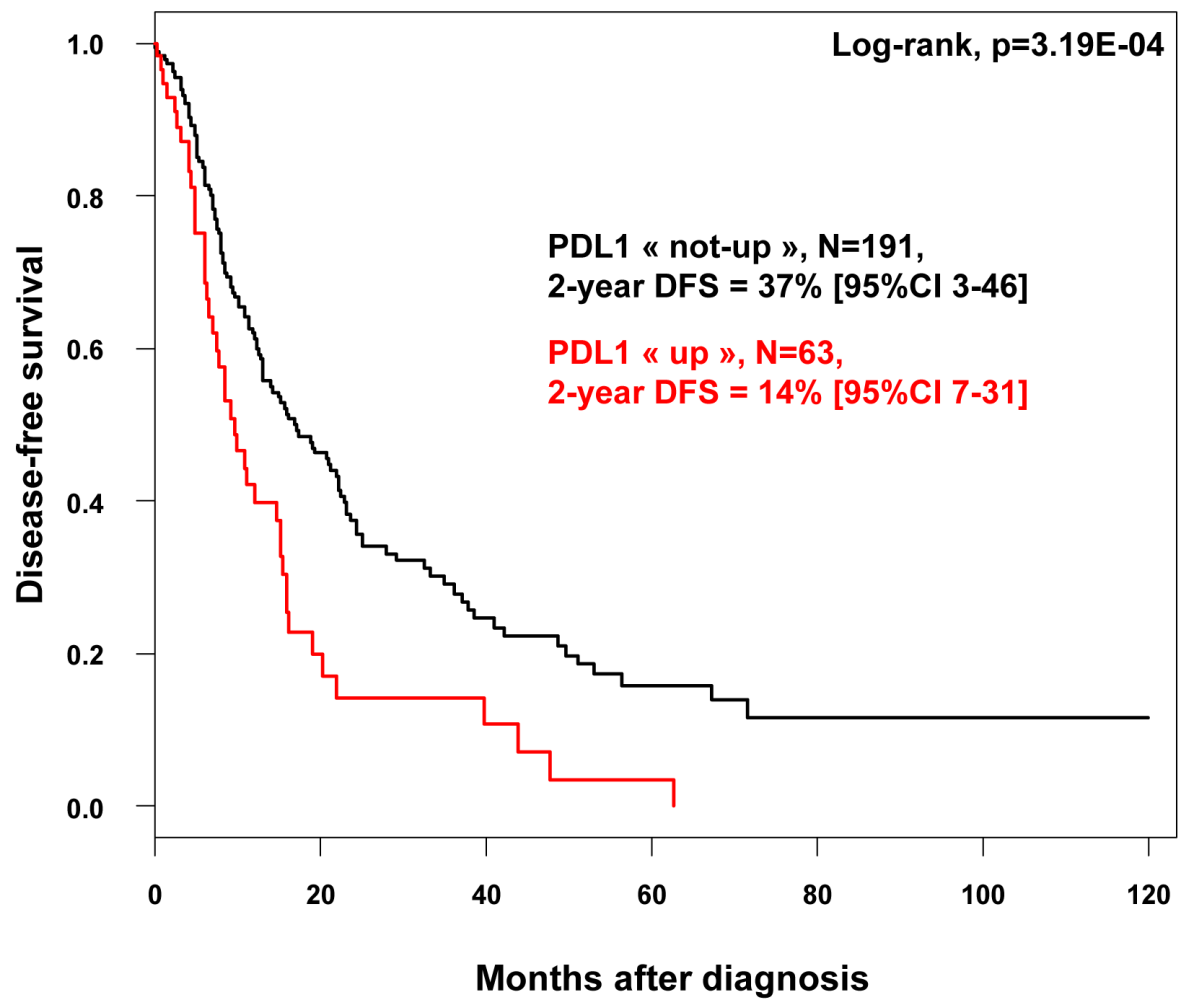

Figure 1: Disease-free survival according to PDL1 mRNA expression in patients with pancreatic cancer. Kaplan-Meier DFS curves in patients with high and low expression in the whole population.

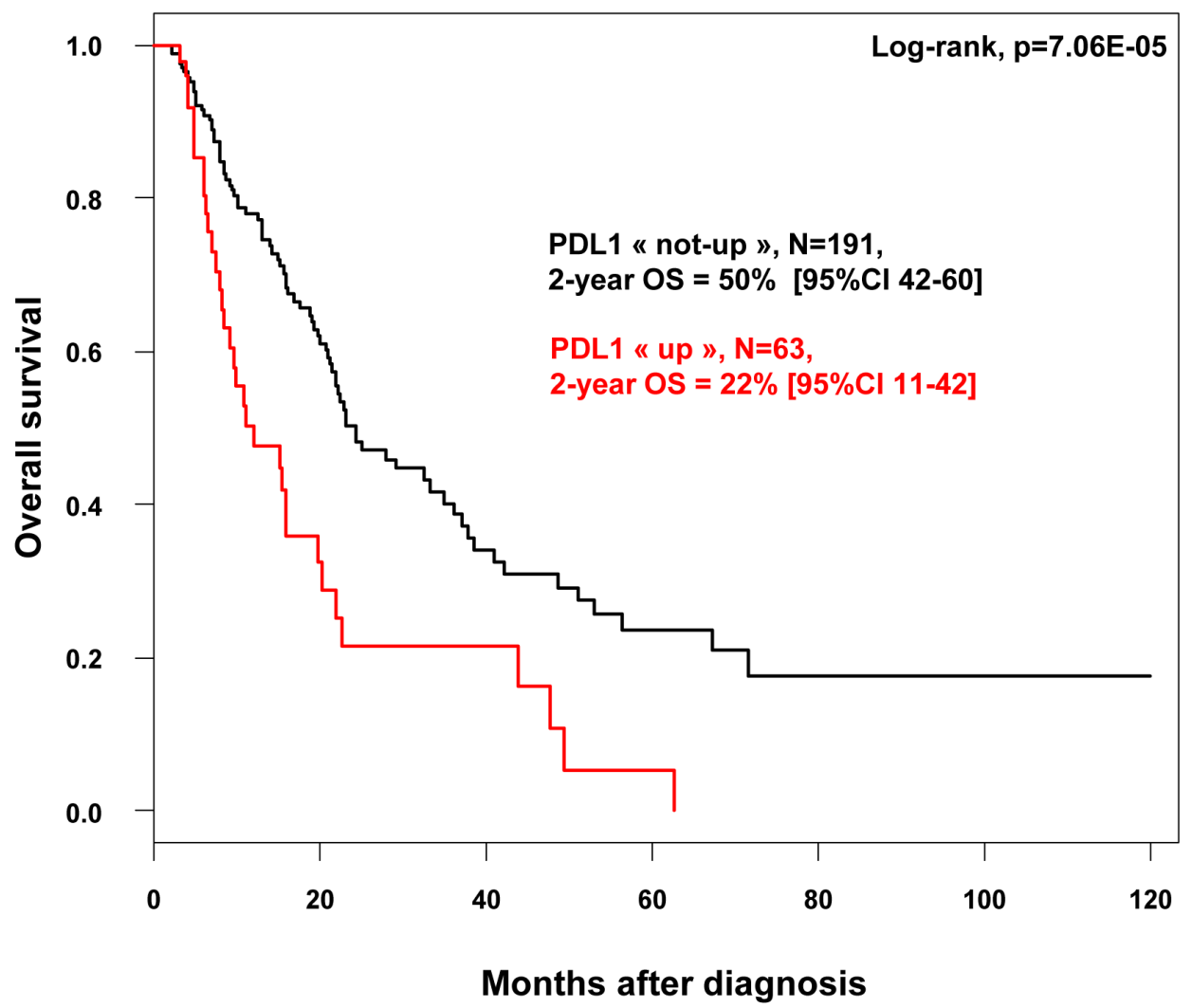

Figure 2: Overall survival according to PDL1 mRNA expression in in patients with pancreatic cancer. Kaplan-Meier OS curves in patients with high and low expression in the whole population. 
Table 1: PDL1 expression and clinicopathological features

\begin{tabular}{|c|c|c|c|c|c|}
\hline \multirow{2}{*}{\multicolumn{2}{|c|}{ Characteristics }} & \multicolumn{3}{|c|}{ PDL1 expression groups } & \multirow[b]{2}{*}{$p$} \\
\hline & & $N$ & not-up $(N=366)$ & up $(N=87)$ & \\
\hline \multicolumn{2}{|c|}{ Median age, years (range) } & 207 & $65(32-88)$ & $64.5(44-84)$ & 0.929 \\
\hline \multirow[t]{3}{*}{ Sex } & & & & & 0.336 \\
\hline & female & 128 & $92(44 \%)$ & $36(51 \%)$ & \\
\hline & male & 154 & $119(56 \%)$ & $35(49 \%)$ & \\
\hline \multicolumn{2}{|c|}{ Pathological tumor size (pT) } & & & & 0.113 \\
\hline & 1 & 8 & $6(4 \%)$ & $2(4 \%)$ & \\
\hline & 2 & 32 & $29(19 \%)$ & $3(6 \%)$ & \\
\hline & 3 & 161 & $117(76 \%)$ & $44(88 \%)$ & \\
\hline & 4 & 3 & $2(1 \%)$ & $1(2 \%)$ & \\
\hline \multicolumn{2}{|c|}{ Pathological lymph node status (pN) } & & & & 0.292 \\
\hline & negative & 62 & $50(33 \%)$ & $12(24 \%)$ & \\
\hline & positive & 139 & $102(67 \%)$ & $37(76 \%)$ & \\
\hline \multicolumn{2}{|c|}{ Pathological type } & & & & 1.000 \\
\hline & ductal & 422 & $341(93 \%)$ & $81(93 \%)$ & \\
\hline & other & 31 & $25(7 \%)$ & $6(7 \%)$ & \\
\hline \multicolumn{2}{|c|}{ Pathological tumor grade } & & & & 0.511 \\
\hline & 1 & 33 & $26(17 \%)$ & $7(14 \%)$ & \\
\hline & 2 & 102 & $79(53 \%)$ & $23(47 \%)$ & \\
\hline & 3 & 63 & $44(30 \%)$ & $19(39 \%)$ & \\
\hline \multirow[t]{3}{*}{ Surgery } & & & & & 1.000 \\
\hline & no & 1 & $1(0 \%)$ & $0(0 \%)$ & \\
\hline & yes & 452 & $365(100 \%)$ & $87(100 \%)$ & \\
\hline \multicolumn{2}{|c|}{ Bailey's molecular subtypes } & & & & $1.00 \mathrm{E}-04$ \\
\hline & $\mathrm{ADEX}^{*}$ & 109 & $95(26 \%)$ & $14(16 \%)$ & \\
\hline & immunogenic & 69 & $53(14 \%)$ & $16(18 \%)$ & \\
\hline & pancreatic progenitor & 101 & $93(25 \%)$ & $8(9 \%)$ & \\
\hline & squamous & 174 & $125(34 \%)$ & $49(56 \%)$ & \\
\hline \multicolumn{2}{|c|}{ Median DFS follow-up, months (range) } & 254 & $9.86(1-84)$ & $1.30(1-24)$ & $1.77 \mathrm{E}-05$ \\
\hline \multicolumn{2}{|c|}{ 2-year DFS } & 254 & $37 \%[0.3-0.46]$ & $14 \%[0.07-0.31]$ & $3.19 \mathrm{E}-04$ \\
\hline \multicolumn{2}{|c|}{ Median OS follow-up, months (range) } & 254 & $9.53(1-84)$ & $2.99(1-31)$ & 4.14E-05 \\
\hline \multicolumn{2}{|c|}{ 2-year OS } & 254 & $50 \%[0.42-0.6]$ & $22 \%[0.11-0.42]$ & $7.06 \mathrm{E}-05$ \\
\hline
\end{tabular}

* ADEX, aberrantly differentiated endocrine exocrine 
Table 2: Univariate and multivariate Cox regression analyses for DFS

\begin{tabular}{|c|c|c|c|c|c|c|c|}
\hline \multirow{2}{*}{\multicolumn{2}{|c|}{ Characteristics }} & \multicolumn{3}{|c|}{ Univariate } & \multicolumn{3}{|c|}{ Multivariate } \\
\hline & & $\mathrm{N}$ & $\mathrm{HR}[95 \mathrm{CI}]$ & p & $\mathrm{N}$ & HR [95CI] & p \\
\hline Age & & 182 & $1.02[1-1.03]$ & 0.0785 & 174 & $1.02[1-1.03]$ & 0.091 \\
\hline Sex & male vs. female & 212 & $1.12[0.79-1.57]$ & 0.529 & & & \\
\hline \multirow[t]{2}{*}{ pT } & $2 \mathrm{vs} .1$ & 180 & $0.93[0.26-3.4]$ & $4.06 \mathrm{E}-02$ & 174 & $0.51[0.13-1.95]$ & 0.322 \\
\hline & $3 v s .1$ & & $2.02[0.63-6.4]$ & & 174 & $0.64[0.18-2.25]$ & 0.490 \\
\hline $\mathrm{pN}$ & posvs.neg & 177 & $1.83[1.16-2.88]$ & $8.94 \mathrm{E}-03$ & 174 & $1.49[0.9-2.48]$ & 0.125 \\
\hline Type & other vs. ductal & 254 & $0.45[0.24-0.83]$ & $1.12 \mathrm{E}-02$ & 174 & $0.84[0.41-1.71]$ & 0.630 \\
\hline \multirow[t]{2}{*}{ Grade } & $2 \mathrm{vs} .1$ & 180 & $1.70[0.92-3.15]$ & $1.40 \mathrm{E}-02$ & 174 & $1.21[0.64-2.3]$ & 0.551 \\
\hline & $3 v 5.1$ & & $2.46[1.31-4.61]$ & & 174 & $1.58[0.83-3.01]$ & 0.166 \\
\hline PDL1 group & up vs. not-up & 254 & $1.9[1.33-2.7]$ & 4.04E-04 & 174 & $1.75[1.12-2.74]$ & $1.49 \mathrm{E}-02$ \\
\hline
\end{tabular}

Table 3: Univariate and multivariate Cox regression analyses for OS

\begin{tabular}{|c|c|c|c|c|c|c|c|}
\hline \multirow{2}{*}{\multicolumn{2}{|c|}{ Characteristics }} & \multicolumn{3}{|c|}{ Univariate } & \multicolumn{3}{|c|}{ Multivariate } \\
\hline & & $\mathbf{N}$ & $\mathrm{HR}[95 \mathrm{Cl}]$ & $\mathbf{p}$ & $\mathbf{N}$ & HR [95Cl] & p \\
\hline Age & & 182 & $1.03[1-1.05]$ & $1.86 \mathrm{E}-02$ & 174 & $1.03[1-1.06]$ & $1.87 \mathrm{E}-02$ \\
\hline Sex & male vs. female & 212 & $1.05[0.69-1.59]$ & 0.818 & & & \\
\hline \multirow[t]{2}{*}{ pT } & 2 vs. 1 & 180 & $1.31[0.15-11.3]$ & 2.74E-02 & 174 & $0.6[0.06-6.12]$ & 0.663 \\
\hline & 3 vs. 1 & & $3.98[0.55-28.9]$ & & 174 & $0.84[0.05-13.44]$ & 0.899 \\
\hline $\mathrm{pN}$ & posvs.neg & 177 & $2.02[1.11-3.69]$ & $2.14 \mathrm{E}-02$ & 174 & $1.4[0.68-2.88]$ & 0.365 \\
\hline Type & othervs. ductal & 254 & $0.15[0.05-0.47]$ & $1.15 \mathrm{E}-03$ & 174 & $0.59[0.17-2.04]$ & 0.407 \\
\hline \multirow[t]{2}{*}{ Grade } & 2 vs. 1 & 180 & $2.27[0.93-5.50]$ & $1.81 E-02$ & 174 & $1.47[0.59-3.67]$ & 0.410 \\
\hline & 3vs. 1 & & $3.45[1.42-8.42]$ & & 174 & $1.85[0.74-4.6]$ & 0.185 \\
\hline$P D L 1$ group & up vs. not-up & 254 & $2.22[1.48-3.33]$ & $1.08 \mathrm{E}-04$ & 174 & $2.36[1.34-4.16]$ & $2.96 \mathrm{E}-03$ \\
\hline
\end{tabular}

not-up" group. In univariate analysis (Table 2), PDL1 expression, large pathological tumor size, lymph node involvement, pathological type, and high tumor grade were associated with DFS, whereas age and sex were not. In multivariate analysis, $P D L 1$ expression remained the sole prognostic feature for DFS (Table 2).

Similar results were observed for OS. With a median follow-up of 7.5 months (range, 1-84) months, 120 patients died, and the 2-year OS was 44\% (95\%CI, 37-53). As shown in Figure 2, the 2-year OS rate was 50\% $(95 \% \mathrm{CI}, 42-60)$ in the "PDL1-not-up" group versus $22 \%$ (95\%CI, 11-42] in the "PDL1-up" group ( $p=7.06 \mathrm{E}-05$, log-rank test). The median OS was 6.4 months (range, 1 to 63) in "PDL1-up" group versus 11.4 months (range, 1 to 156) in "PDL1-not-up" group. In univariate analysis (Table 3), PDL1 expression, age, large pathological tumor size, lymph node involvement, pathological type, and high tumor grade, were associated with poor OS, whereas sex was not. The HR for death was 2.22 (95\%CI, 1.48$3.33)$ in the "PDL1-up" group versus "PDL1-not-up" group ( $p=0.0001$, Wald test). In multivariate analysis, PDL1 expression and age remained the sole prognostic features for OS (Table 3). Of note, PDL1 expression remains an independent prognostic factor for DFS and OS in multivariate analysis including the Bailey's molecular classification (data not shown).

\section{PDL1 expression and associated biological processes}

Supervised analysis applied to the largest data set (TCGA set, $N=178$ ) identified 2,405 genes differentially expressed between the tumors with $(N=46)$ versus without $(N=132) P D L 1$ upregulation, including 1,624 genes upregulated and 781 genes downregulated in the "PDL1-up" samples (Supplementary Figure 2A2B; Supplementary Table 2). The robustness of this gene signature was confirmed in the pool of all other independent sets including a total of 275 tumors by using a metagene-based prediction score: as shown in Supplementary Figure 2C, the score was higher in the "PDL1-up" samples than in the "PDL1-not-up" samples ( $p=2.0 \mathrm{E}-14$, Student t-test). Ontology analysis of these 2,405 genes (Supplementary Table 3) revealed that "PDL1up" tumors overexpressed genes involved in the regulation 
of the local immune response. More specifically, we found that numerous upregulated genes are involved in immune response, notably in inflammatory response (mostly TollLike Receptors, molecules of the complement cascade, but also CD163, CD302, IL1R1, IL6, IL8, and molecules involved in the synthesis of leukotrienes, phospholipids and prostaglandins) and lymphocytes chemotaxis. Major actors of leukocyte activation $(C D 2, C D 3 D, C D 3 E, C D 3 G$, CD4, CD5, CD8A, CD8B, CD27, CD28, CD38, CD40LG, CD80, CD86, CD226, CD247, HLA-DOA, HLA-DRA, KLRK1, TNFSF4, TNFSF14, TNFRSF8, IL2RA, IL7R, IL11, IL12RB1, IL12RB2, IL21R, IL31RA, IFNG, IKZF1, $J A K 2, P I K 3 C G, E O M E S, R O R A, T B X 21 \ldots)$ were also positively correlated with $P D L 1$ expression, attesting of a strong recruitment and tumor infiltration by T-cells in the "PDL1-up" group. However, numerous genes related to negative lymphocyte regulation were also present (BTLA, CTLA4, FOXP3, HAVCR2, HIF1A, IL10, IL1RAP, IDO1, KLRC1, LAG3, PDCD1LG2, VSIG4, SPN, SLA2, TGFBR2, TGFB2, TGFB3, TIGIT...), notably all the hallmark molecules of exhausted T-cells (BTLA, HAVCR2, $L A G 3, P D 1)$. Many genes upregulated in the "PDL1-notup" group are involved in cell metabolism.

\section{PDL1 expression and immune response-related features}

Given the role of PDL1 in immunity, we searched for correlations between the two PDL1 expression-based groups and immunity-related features (Supplementary Table 4). No correlation was found with the percentage of tumor-infiltrating lymphocytes (TILs), which was available in the TCGA data set, as previously reported [27, 41]. We found a correlation with the three Palmer's B-cell, T-cell, and CD8+ T-cell gene expression signatures, the expression module of each signature being higher in the "PDL1-up" group than in the "PDL1-not-up" group. Out of four gene expression signatures tested and reflecting the cytotoxic T-cell response, only one, the "LCK signature", was associated with the PDL1 groups, whereas the three other ones ("medullary breast cancer", "28-kinase immune", and "immune response") were not. Finally, we found that the probability of activation of immunerelated pathways such as IFN $\alpha$ and IFN $\gamma$ was higher in the "PDL1-up" group. Altogether, these results suggested that PDL1 expression in pancreatic cancer is associated with some degree of lymphocyte infiltration and signs of antitumor T-cell response.

\section{Comparison of PDL1-associated immune response-related features in pancreatic cancer, breast cancer and GIST}

Given the opposite prognostic value of PDL1 expression in pancreatic cancer (unfavorable value) when compared with breast cancer and GIST (favorable value) $[23,25]$, we compared the biological and immune features associated with PDL1 expression in these cancers. First, we observed that the correlations described in the previous section were much weaker (Supplementary Table 4) than those we had previously reported in breast cancers and GISTs [23, 25], where PDL1 upregulation was associated with stronger cytotoxic T-cell responses. The strength of association between $P D L 1$ expression and the probability of activation of immune-related pathways (IFN $\alpha, \operatorname{IFN} \gamma$ ) was also much lower in pancreatic carcinomas than in breast cancers and GISTs (Supplementary Table 4). This would be in line with the highlighted exhausted lymphocyte profile observed in the pancreatic carcinoma PDL1 signature. Second, we compared the three PDL1 gene signatures (pancreas, breast, GIST) that we generated de novo from the 12,091 genes common to the three studies and using the same parameters of supervised analysis (moderated t-test, $p<5 \%, q<25 \%$, $|\mathrm{FC}|>1.5 \mathrm{x}$ ). The comparison of signatures (pancreas 1587 genes, breast 941 genes, GIST 1432 genes) revealed interesting differences regarding immune features (Supplementary Table 5). For example, all major markers of exhausted T-cells (BTLA, HAVCR2, LAG3, PD1) were present and strongly differential in the pancreas signature only. $F O X P 3$, the master transcription factor for regulatory T-cells (Tregs), and its effective cytokine IL10, were also upregulated in the "PDL1-up" group of pancreatic cancers. The genes overexpressed in the PDL1-up group of pancreatic cancers also included CD33, but not CD14, which is concordant with the presence of myeloid-derived suppressor cells (MDSCs). Components of the S100A8/A9 complex, inflammatory mediators of immune suppression by MDSCs, were also overexpressed in this group. Finally, many genes related to antigen processing and presentation of exogenous peptide antigen via MHC class-I (B2M, $C Y B B, H L A-A$, HLA-B, HLA-C, HLA-E, HLA-F, HLA-G, NCF2, NCF4, PSMB8, PSMB9, PSMB10, PSME1, TAP1, $T A P 2, T A P B P$ ) were present in the PDL1 breast and GIST signatures, but not in the pancreatic signature, notably on the aspects of TAP-dependent mechanisms of antigen presentation, endocytosis, phagosome maturation ( $C Y B B$, $L T F, N C F 1, N C F 2, N C F 4, R A B 31)$ and proteasomal ubiquitin-independent protein catabolic process. That was clearly shown by the ontology analysis of genes upregulated in these three signatures (Supplementary Table 6). Altogether, these observations converged toward a poorer efficiency of anti-tumor response in pancreatic carcinoma than in breast cancer and GIST, which can be monitored through PDL1 transcript evaluation.

\section{DISCUSSION}

Overexpression of PDL1 by tumor cells has been noted in a number of human cancers, and the blockade of the PD1-PDL1 pathway is a promising therapeutic 
approach in oncology. PDL1 inhibitors produced antitumor responses in mouse models of pancreatic cancers $[27,41,43]$. In this study, we have analyzed the PDL1 mRNA expression in 453 clinical pancreatic cancer samples: PDL1 upregulation was observed in $19 \%$ of cases and was associated with shorter DFS and OS in multivariate analysis.

To date, PDL1 expression in cancers has been mainly studied at the protein level using IHC. However, such analysis on paraffin-embedded slides has been a challenge until recently, with different non-standardized techniques and scoring systems making the results not conclusive [44, 45]. Indeed, the measurement of PDL1 expression by IHC is not yet standardized and many discordant results have been reported across studies, notably regarding the prognostic value of PDL1 expression [46]. Several antibodies are available but lack specificity and reproducibility $[45,47,48]$ and the optimal positivity cut-off is not defined [49]. Given our current state of knowledge, the use of different PDL1 IHC assays as a "companion diagnostic" still raises many issues. Efforts to clarify the optimal IHC assay are ongoing for improvements, in most solid tumors, and in particular in pancreatic cancer [50]. On the other hand, a positive relationship between protein and mRNA PDL1 expression (using in situ fluorescent RNAscope paired-primer assay or ISH) has been reported in breast carcinoma [51].

In the present retrospective study, we have based our analysis on mRNA expression measured using DNA microarrays or RNASeq. Such approach allowed us to avoid the limitations of IHC and to work on a very large series of samples. Furthermore, the whole-genome aspect provided opportunity for better understanding how this co-inhibitory signaling molecule might contribute to the suppression of antitumor immunity in the tumor's microenvironment. Indeed, personalized cancer immunotherapy should integrate in the future not only the evaluation of PDL1 expression but also specific mechanisms through which cancer adapts to evade an antitumor immune response. We believe that gene expression profiling might contribute to highlight some of the markers that should be analyzed in this prospect, together with PDL1. Further studies are required to identify the right biomarkers able to predict and monitor response to the different PDL1/PD1 blocking agents. This might lead to a more or less complex algorithm that pathologists and biologists should consider rapidly [52].

To our knowledge, only six studies in the literature have described $P D L 1$ expression in pancreatic carcinoma and correlations with tumor features [27, 37-41]. Four studies were based on IHC [27, 37, 40, 41] and included from 8 to 81 patients, and two were based on IHC and qRT-PCR $[38,39]$ and included 40 patients each. We found $P D L 1$ upregulation in $19 \%$ of samples, lower than the percentages reported in these smaller series (from 32 to $62 \%$ ), likely because of different scoring systems and analytic levels. Analysis of correlations with clinicopathological features showed discordant results between all studies including ours: we and others [27, 39] did not find any correlation with patients' age and sex, nor with pathological tumor size, lymph node status and grade, whereas two studies reported correlations between PDL1 expression and higher stage and higher tumor grade [37, 38]. By contrast, the unfavorable prognostic value of $P D L 1$ expression we report here was found in all three previous small series [27, 37, 39]; importantly, the larger size of our series (254 non-metastatic cases informative for survival) allowed the confirmation of its impact in multivariate analysis. Finally, we found a correlation between the PDL1 status and a recent transcriptional classification of pancreatic ductal carcinoma [42]: 56\% of PDL1-up tumors were in the squamous subtype, and PDL1 mRNA was up-regulated in the squamous subtype versus each other subtype (pancreatic progenitor; immunogenic; and aberrantly differentiated endocrine exocrine). Interestingly, PDL1 expression remains an independent prognostic factor in multivariate analysis including the Bailey's molecular subtypes. Considering the immunosuppressive function of PDL1, it was not surprising to find expression associated with poor survival, as already reported in other cancers [52-57]. However, PDL1 expression has also been associated with favorable outcome in certain cancers such as breast and lung cancers [23, 24, 46, 51] and GIST [25]. Such opposition regarding the prognostic value of PDL1 expression in different cancers led us to study and compare the association between PDL1 expression and biological and immune features. We thus looked at the genes correlating with $P D L 1$ expression to provide a better biological characterization of $P D L 1$-up pancreatic carcinomas. These genes were almost exclusively related to immune cells and attested of tumor infiltration by lymphocytes. The comparison between three PDL1 signatures revealed a stronger cytotoxic profile correlated with anti-tumor pathways activation (IFN $\alpha$ and IFN $\gamma$ ) in breast cancers and GISTs, suggesting a sustained activation of anti-tumor T-cells in breast cancers and GISTs of good prognosis. In these cases, we hypothesize that $P D L 1$ was upregulated because of a negative feedback loop that follows cytotoxic cells activation, notably through the production of IFNG, a, a known regulator of PDL1 expression. In the pancreatic cancer study, we also found IFNG expression as being correlated with PDL1 expression, as reported by others [39]. However, this increased expression of IFNG was also associated to several elements that were not or were only partially present in the breast and GIST PDL1 signatures, and that might provide some explanatory hints. First, all the typical markers related to T-cell exhaustion were upregulated in the "PDL1-up" pancreas group, in addition to IDOI and CTLA4, known as major actors attenuating T-cell immune response, in parallel to a major hypoxic environment (HIF1A). Second, FOXP3, the master transcription 
factor for Tregs, and its effective cytokine IL10, were associated with $P D L 1$ upregulation in pancreatic cancers. Interleukin-10 has strong immunosuppressive effects on lymphocyte activation, notably $\mathrm{T}_{\mathrm{H}} 1$ cytotoxic cells. In agreement with our data, Geng et al reported an increased prevalence of tumor-infiltrating Tregs in PDL1-positive pancreatic carcinomas [38, 39]. In parallel, IL-10 has been associated with poor survival in pancreatic cancer [39]. One explanation might be that PDL1 stimulates IL-10 production [58]. Activation of Tregs, via IL-10 production, might thus represent a mechanism of downregulating the antitumor response through $P D L 1$-upregulation. Third, we found upregulation of the $C D 33$ transcript, but not of $C D 14$, suggesting the presence of myeloidderived suppressor cells (MDSCs), previously reported as increased in pancreatic cancer [59]. MDSCs suppress T-cell responses in cancer patients and animal models [59]. In agreement with their likely infiltration, we found upregulation of the S100A8/A9 complex, an inflammatory mediator of immune suppression by MDSCs in PDL1upregulated pancreatic cancers. This specific complex was previously involved in PDL1 upregulation [60]. Finally, when looking at genes present in the breast and GIST PDL1-up signatures, but absent from the pancreas signature, we found many genes related to antigen presentation, including endocytosis and proteasome processing, highlighting a defect in antigen processing and presentation to anti-tumor immunity, notably to T-cells, in pancreatic carcinoma. Indeed, cytotoxic T-cells recognize, via their T-cell receptors (TCRs) and CD8 coreceptors, small antigenic peptides presented by the major histocompatibility complex (pMHC) of class I on the surface of all nucleated cells, including malignant cells. Our signature clearly demonstrated a down-modulation of most MHC class I members (HLA-A/B/C, HLA-E/ $\mathrm{F} / \mathrm{G})$. This is a classical mechanism of escape in various malignant cells. It has been widely speculated that IL-10 could favor the development of tumors through immunosuppressive mechanisms, including the modulation of antigen-presenting cells and especially dendritic cells functions $[61,62]$. Altogether, these differences suggested that PDL1-up pancreatic cancers were more enriched in inhibitory molecules and pro-tumoral populations (Treg, MDSC), than PDL1-up breast cancers and GIST. Among the incriminated actors, some (IFNG, IL10, MDSC...) are directly implicated in and might explain the upregulation of PDL1 in pancreatic cancer. Altogether, this might explain the more pronounced escape to anti-tumor immunity, and the negative prognostic value of $P D L 1$ transcript in this cancer.

In conclusion, we showed that PDL1 mRNA expression, observed in $19 \%$ of cases, represents an independent poor-prognosis feature for DFS and OS in pancreatic cancer. The main strength of our study lies in the number of samples analyzed (more than 450) and the parallel biological analyses. Limitations include the retrospective nature and associated biases, including the absence of information with respect to survival for all samples, and the use of gene expression profiling that quantifies expression level of both epithelial and stromal cells. Analysis of larger series, retrospective, then prospective is needed, as well as protein analysis when reliable antibodies are available. If confirmed, PDL1 expression might refine the prognostication of operable pancreatic cancer and improve our ability to better tailor adjuvant therapy. From a therapeutic point of view, PDL1 expression might guide the use of PD1/PDL1 inhibitors that could reactivate inhibited T-cells to increase the antitumor immune response when associated with primers of T-cell response such as immunogenic chemotherapy [63] or vaccines $[41,64]$. Functional and clinical validation of this hypothesis is urgently warranted.

\section{MATERIALS AND METHODS}

\section{Gene expression data sets}

We gathered clinicopathological and gene expression data of clinical pancreatic carcinoma samples from nine publicly available data sets [65-72] (https:// tcga-data.nci.nih.gov/tcga/) comprising at least one probe set representing $P D L 1$. Data were collected from the National Center for Biotechnology Information (NCBI)/ Genbank GEO, ArrayExpress, and TCGA databases. The nine data sets are described in Supplementary Table 7. Samples were profiled using whole-genome DNA microarrays (Affymetrix, Agilent, or Illumina) and RNASeq (Illumina). The pooled data set contained 565 samples, including 453 primary cancer samples and 112 normal pancreatic samples. The study was approved by our institutional board.

\section{Gene expression data analysis}

Data analysis required pre-analytic processing. First, we normalized each DNA microarray-based data set separately, by using quantile normalization for the available processed data from non-Affymetrix-based sets (Agilent, Illumina), and Robust Multichip Average (RMA) with the non-parametric quantile algorithm for the raw Affymetrix data sets. Normalization was done in R using Bioconductor and associated packages. Then, we mapped hybridization probes across the different technological platforms present. We used SOURCE (http://smd.stanford. edu/cgi-bin/source/sourceSearch) and EntrezGene (Homo sapiens gene information $\mathrm{db}$, release from 09/12/2008, $\mathrm{ftp}: / / \mathrm{ftp}$. ncbi.nlm.nih.gov/gene/) to retrieve and update the non-Affymetrix gene chips annotations, and NetAffx Annotation files (www.affymetrix.com; release from 01/12/2008) for the Affymetrix annotations. The probes 
were then mapped according to their EntrezGeneID. When multiple probes represented the same GeneID, we retained the one with the highest variance in a particular dataset. PDL1 (CD274) tumour expression was measured by analysing different probe sets whose identity and specificity were verified using the NCBI program BLASTN 2.2.31+ (Supplementary Table 8). For the TCGA data, we used the available normalized RNASeq data that we $\log _{2}$-transformed. Next, we corrected the nine studies for batch effects using $\mathrm{z}$-score normalization. Briefly, for each gene expression value in each study separately, all values were transformed by subtracting the mean of the gene in that dataset divided by its standard deviation, mean and standard deviation being measured on primary cancer samples only. Global data set was obtained by concatenation of the nine normalized sets by matching their EntrezGeneID. We performed principal component analysis (PCA) using the top 2,000 most variable genes extracted from the nine data sets, before and after normalization, to verify the accuracy of the normalization in removing the set-specific variation in gene expression (Supplementary Figure 3). PDL1 expression, before and after normalization, is shown for each dataset in Supplementary Figure 4. PDL1 expression in tumors (T) was measured as discrete value after comparison with mean expression in the 112 normal pancreatic samples (NP): upregulation, thereafter designated "up" was defined by a T/NP ratio $\geq 2$ and no upregulation ("not-up") by a T/ NP ratio $<2$.

Because of the involvement of PDL1 in immunity, we analyzed gene expression signatures linked to immune response in cancers. Each of the following signatures was applied in each data set separately: three Palmer's B-cell, T-cell, and CD8+ T-cell signatures [73], four signatures reflecting the cytotoxic $\mathrm{T}$-cell response including the "LCK signature" [74], the "medullary breast cancer" signature [75], the "28-kinase immune" signature [76], and the "immune response" signature [77], and two Gatza's signatures of IFN $\alpha$ and IFN $\gamma$ biological pathway activity [78]. Finally, to explore more-in-depth the biological pathways linked to $P D L 1$ expression in pancreatic cancer, we applied a supervised analysis by using the largest data set (TCGA: 178 samples) as learning set, and the other data sets as independent validation sets (275 samples). In the learning set, we compared the expression profiles of 20,531 genes between tumors with $(N=46)$ versus without $(N=132) P D L 1$ upregulation using a moderated t-test with empirical Bayes statistic [79] included in the limma R packages. False discovery rate (FDR) [80] was applied to correct the multiple testing hypothesis and significant genes were defined by the following thresholds: $p<5 \%, q<25 \%$ and fold change (FC) superior to $|1.5 \mathrm{x}|$. Ontology analysis of the resulting gene list was based on GO biological processes and Biocarta ontologies of the Database for Annotation, Visualization and Integrated Discovery (DAVID; david.abcc.ncifcrf.gov/). We verified the robustness of the resulting gene list in each validation set (a total of 41 tumors with and 234 without PDL1 upregulation were represented) separately by computing for each tumor a metagene-based prediction score defined by the difference between the "metagene PDL1-up" (mean expression of all genes upregulated in the "PDL1-up" group) and the metagene PDL1-not-up" (mean expression of all genes upregulated in the "PDL1-not-up" group). This score was then compared between the "PDL1-up" and "PDL1-not-up samples.

\section{Statistical analysis}

Correlations between tumor groups and clinicopathological features were analyzed using the t-test or the Fisher's exact test (variables with 2 groups) when appropriate. Disease-free survival (DFS) was calculated from the date of diagnosis until the date of distant relapse or death from pancreatic cancer. Overall survival (OS) was calculated from the date of diagnosis to the date of death from pancreatic cancer. Follow-up was measured from the date of diagnosis to the date of last news for event-free patients. Survivals were calculated using the Kaplan-Meier method and curves were compared with the log-rank test. Univariate and multivariate survival analyses were done using Cox regression analysis (Wald test). Variables tested in univariate analyses included patients' age at time of diagnosis (continuous value), sex, pathological features including pathological type, tumor size (T2 and T3 vs $\mathrm{T} 1$ ), regional lymph node status (positive $v s$ negative), tumor grade ( 2 and 3 vs 1 ), and PDL1 expression ("up" vs "not-up"). Variables with a $p$-value $<0.10$ were tested in multivariate analysis. All statistical tests were two-sided at the $5 \%$ level of significance. Statistical analysis was done using the survival package (version 2.30) in the $\mathrm{R}$ software (version 2.9.1; http://www.cran.r-project.org/). We followed the reporting REcommendations for tumor MARKer prognostic studies (REMARK criteria) [81].

\section{ACKNOWLEDGEMENTS}

Our work is supported by Inserm, Institut PaoliCalmettes, and SIRIC (INCa-DGOS-Inserm 6038 grant).

\section{CONFLICTS OF INTEREST}

The authors have no conflict of interest to declare.

\section{REFERENCES}

1. Jemal A, Bray F, Center MM, Ferlay J, Ward E, Forman D. Global cancer statistics. CA Cancer J Clin. 2011; 61: 69-90.

2. Rahib L, Smith BD, Aizenberg R, Rosenzweig AB, Fleshman JM, Matrisian LM. Projecting cancer incidence and deaths to 2030: the unexpected burden of thyroid, liver, 
and pancreas cancers in the United States. Cancer Res. 2014; 74: 2913-2921.

3. Nowak NJ, Gaile D, Conroy JM, McQuaid D, Cowell J, Carter R, Goggins MG, Hruban RH, Maitra A. Genomewide aberrations in pancreatic adenocarcinoma. Cancer Genet Cytogenet. 2005; 161: 36-50.

4. Buchler M, Friess H, Schultheiss KH, Gebhardt C, Kubel R, Muhrer KH, Winkelmann M, Wagener T, Klapdor R, Kaul M, Müller G, Schulz G, Beger HG. A randomized controlled trial of adjuvant immunotherapy (murine monoclonal antibody 494/32) in resectable pancreatic cancer. Cancer. 1991; 68: 1507-1512.

5. Friess H, Buchler M, Kruger M, Beger HG. Treatment of duct carcinoma of the pancreas with the LH-RH analogue buserelin. Pancreas. 1992; 7: 516-521.

6. Amedei A, Niccolai E, Prisco D. Pancreatic cancer: role of the immune system in cancer progression and vaccinebased immunotherapy. Hum Vaccin Immunother. 2014; 10: 3354-3368.

7. Tewari N, Zaitoun AM, Arora A, Madhusudan S, Ilyas M, Lobo DN. The presence of tumour-associated lymphocytes confers a good prognosis in pancreatic ductal adenocarcinoma: an immunohistochemical study of tissue microarrays. BMC Cancer. 2013; 13: 436.

8. Gabitass RF, Annels NE, Stocken DD, Pandha HA, Middleton GW. Elevated myeloid-derived suppressor cells in pancreatic, esophageal and gastric cancer are an independent prognostic factor and are associated with significant elevation of the Th2 cytokine interleukin-13. Cancer Immunol Immunother. 2011; 60: 1419-1430.

9. Hiraoka N, Onozato K, Kosuge T, Hirohashi S. Prevalence of FOXP3+ regulatory $\mathrm{T}$ cells increases during the progression of pancreatic ductal adenocarcinoma and its premalignant lesions. Clin Cancer Res. 2006; 12: 54235434.

10. Fukunaga A, Miyamoto M, Cho Y, Murakami S, Kawarada Y, Oshikiri T, Kato K, Kurokawa T, Suzuoki M, Nakakubo Y, Hiraoka K, Itoh T, Morikawa T, et al. CD8+ tumorinfiltrating lymphocytes together with $\mathrm{CD} 4+$ tumorinfiltrating lymphocytes and dendritic cells improve the prognosis of patients with pancreatic adenocarcinoma. Pancreas. 2004; 28: e26-31.

11. De Monte L, Reni M, Tassi E, Clavenna D, Papa I, Recalde H, Braga M, Di Carlo V, Doglioni C, Protti MP. Intratumor $\mathrm{T}$ helper type 2 cell infiltrate correlates with cancer-associated fibroblast thymic stromal lymphopoietin production and reduced survival in pancreatic cancer. J Exp Med. 2011; 208: 469-478.

12. Ahmadzadeh M, Johnson LA, Heemskerk B, Wunderlich JR, Dudley ME, White DE, Rosenberg SA. Tumor antigenspecific CD8 T cells infiltrating the tumor express high levels of PD-1 and are functionally impaired. Blood. 2009; 114: $1537-1544$.

13. Dong H, Strome SE, Salomao DR, Tamura H, Hirano F,
Flies DB, Roche PC, Lu J, Zhu G, Tamada K, Lennon VA, Celis E, Chen L. Tumor-associated B7-H1 promotes T-cell apoptosis: a potential mechanism of immune evasion. Nature medicine. 2002; 8: 793-800.

14. Francisco LM, Salinas VH, Brown KE, Vanguri VK, Freeman GJ, Kuchroo VK, Sharpe AH. PD-L1 regulates the development, maintenance, and function of induced regulatory T cells. J Exp Med. 2009; 206: 3015-3029.

15. Hamel KM, Cao Y, Wang Y, Rodeghero R, Kobezda T, Chen L, Finnegan A. B7-H1 expression on non-B and non- $\mathrm{T}$ cells promotes distinct effects on $\mathrm{T}$ - and B-cell responses in autoimmune arthritis. European journal of immunology. 2010; 40: 3117-3127.

16. Zou W, Chen L. Inhibitory B7-family molecules in the tumour microenvironment. Nature reviews Immunology. 2008; 8: 467-477.

17. Brahmer JR, Tykodi SS, Chow LQ, Hwu WJ, Topalian SL, Hwu P, Drake CG, Camacho LH, Kauh J, Odunsi K, Pitot HC, Hamid O, Bhatia S, et al. Safety and activity of antiPD-L1 antibody in patients with advanced cancer. N Engl J Med. 2012; 366: 2455-2465.

18. Topalian SL, Hodi FS, Brahmer JR, Gettinger SN, Smith DC, McDermott DF, Powderly JD, Carvajal RD, Sosman JA, Atkins MB, Leming PD, Spigel DR, Antonia SJ, et al. Safety, activity, and immune correlates of anti-PD-1 antibody in cancer. N Engl J Med. 2012; 366: 2443-2454.

19. Powles T, Eder JP, Fine GD, Braiteh FS, Loriot Y, Cruz C, Bellmunt J, Burris HA, Petrylak DP, Teng SL, Shen X, Boyd Z, Hegde PS, et al. MPDL3280A (anti-PD-L1) treatment leads to clinical activity in metastatic bladder cancer. Nature. 2014; 515: 558-562.

20. Taube JM, Klein A, Brahmer JR, Xu H, Pan X, Kim JH, Chen L, Pardoll DM, Topalian SL, Anders RA. Association of PD-1, PD-1 ligands, and other features of the tumor immune microenvironment with response to anti-PD-1 therapy. Clin Cancer Res. 2014; 20: 5064-5074.

21. Herbst RS, Soria JC, Kowanetz M, Fine GD, Hamid O, Gordon MS, Sosman JA, McDermott DF, Powderly JD, Gettinger SN, Kohrt HE, Horn L, Lawrence DP, et al. Predictive correlates of response to the anti-PD-L1 antibody MPDL3280A in cancer patients. Nature. 2014; 515: 563567.

22. Tumeh PC, Harview CL, Yearley JH, Shintaku IP, Taylor EJ, Robert L, Chmielowski B, Spasic M, Henry G, Ciobanu V, West AN, Carmona M, Kivork C, et al. PD-1 blockade induces responses by inhibiting adaptive immune resistance. Nature. 2014; 515: 568-571.

23. Sabatier R, Finetti P, Mamessier E, Adelaide J, Chaffanet M, Ali HR, Viens P, Caldas C, Birnbaum D, Bertucci F. Prognostic and predictive value of PDL1 expression in breast cancer. Oncotarget. 2015; 6: 5449-5464. doi: 10.18632/oncotarget.3216.

24. Bertucci F, Finetti P, Colpaert C, Mamessier E, Parizel M, Dirix L, Viens P, Birnbaum D, van Laere S. PDL1 
expression in inflammatory breast cancer is frequent and predicts for the pathological response to chemotherapy. Oncotarget. 2015; 6: 13506-13519. doi: 10.18632/ oncotarget.3642.

25. Bertucci F, Finetti P, Mamessier E, Pantaleo MA, Astolfi A, Ostrowski J, Birnbaum D. PDL1 expression is an independent prognostic factor in localized GIST. Oncoimmunology. 2015; 4: e1002729.

26. Konishi J, Yamazaki K, Azuma M, Kinoshita I, DosakaAkita H, Nishimura M. B7-H1 expression on non-small cell lung cancer cells and its relationship with tumor-infiltrating lymphocytes and their PD-1 expression. Clin Cancer Res. 2004; 10: 5094-5100.

27. Nomi T, Sho M, Akahori T, Hamada K, Kubo A, Kanehiro H, Nakamura S, Enomoto K, Yagita H, Azuma M, Nakajima Y. Clinical significance and therapeutic potential of the programmed death-1 ligand/programmed death-1 pathway in human pancreatic cancer. Clin Cancer Res. 2007; 13: 2151-2157.

28. Ohigashi Y, Sho M, Yamada Y, Tsurui Y, Hamada K, Ikeda N, Mizuno T, Yoriki R, Kashizuka H, Yane K, Tsushima F, Otsuki N, Yagita H, et al. Clinical significance of programmed death-1 ligand-1 and programmed death-1 ligand-2 expression in human esophageal cancer. Clin Cancer Res. 2005; 11: 2947-2953.

29. Strome SE, Dong H, Tamura H, Voss SG, Flies DB, Tamada K, Salomao D, Cheville J, Hirano F, Lin W, Kasperbauer JL, Ballman KV, Chen L. B7-H1 blockade augments adoptive T-cell immunotherapy for squamous cell carcinoma. Cancer Res. 2003; 63: 6501-6505.

30. Thompson RH, Dong H, Lohse CM, Leibovich BC, Blute ML, Cheville JC, Kwon ED. PD-1 is expressed by tumorinfiltrating immune cells and is associated with poor outcome for patients with renal cell carcinoma. Clin Cancer Res. 2007; 13: 1757-1761.

31. Thompson RH, Gillett MD, Cheville JC, Lohse CM, Dong H, Webster WS, Krejci KG, Lobo JR, Sengupta S, Chen L, Zincke H, Blute ML, Strome SE, et al. Costimulatory B7-H1 in renal cell carcinoma patients: Indicator of tumor aggressiveness and potential therapeutic target. Proceedings of the National Academy of Sciences of the United States of America. 2004; 101: 17174-17179.

32. Hamanishi J, Mandai M, Iwasaki M, Okazaki T, Tanaka Y, Yamaguchi K, Higuchi T, Yagi H, Takakura K, Minato N, Honjo T, Fujii S. Programmed cell death 1 ligand 1 and tumor-infiltrating $\mathrm{CD} 8+\mathrm{T}$ lymphocytes are prognostic factors of human ovarian cancer. Proceedings of the National Academy of Sciences of the United States of America. 2007; 104: 3360-3365.

33. Wintterle S, Schreiner B, Mitsdoerffer M, Schneider D, Chen L, Meyermann R, Weller M, Wiendl H. Expression of the B7-related molecule B7-H1 by glioma cells: a potential mechanism of immune paralysis. Cancer Res. 2003; 63: 7462-7467.

34. Badoual C, Hans S, Merillon N, Van Ryswick C, Ravel
P, Benhamouda N, Levionnois E, Nizard M, Si-Mohamed A, Besnier N, Gey A, Rotem-Yehudar R, Pere H, et al. $\mathrm{PD}-1$-expressing tumor-infiltrating $\mathrm{T}$ cells are a favorable prognostic biomarker in HPV-associated head and neck cancer. Cancer Res. 2013; 73: 128-138.

35. Droeser RA, Hirt C, Viehl CT, Frey DM, Nebiker C, Huber X, Zlobec I, Eppenberger-Castori S, Tzankov A, Rosso R, Zuber M, Muraro MG, Amicarella F, et al. Clinical impact of programmed cell death ligand 1 expression in colorectal cancer. European journal of cancer. 2013; 49: 2233-2242.

36. Spranger S, Spaapen RM, Zha Y, Williams J, Meng Y, Ha TT, Gajewski TF. Up-regulation of PD-L1, IDO, and $\mathrm{T}$ (regs) in the melanoma tumor microenvironment is driven by CD8(+) T cells. Science translational medicine. 2013; 5: 200ra116.

37. Wang L, Ma Q, Chen X, Guo K, Li J, Zhang M. Clinical significance of B7-H1 and B7-1 expressions in pancreatic carcinoma. World J Surg. 2010; 34: 1059-1065.

38. Geng L, Huang D, Liu J, Qian Y, Deng J, Li D, Hu Z, Zhang J, Jiang G, Zheng S. B7-H1 up-regulated expression in human pancreatic carcinoma tissue associates with tumor progression. J Cancer Res Clin Oncol. 2008; 134: 10211027.

39. Loos M, Giese NA, Kleeff J, Giese T, Gaida MM, Bergmann F, Laschinger M, M WB, Friess H. Clinical significance and regulation of the costimulatory molecule B7-H1 in pancreatic cancer. Cancer Lett. 2008; 268: 98109.

40. Song X, Liu J, Lu Y, Jin H, Huang D. Overexpression of B7-H1 correlates with malignant cell proliferation in pancreatic cancer. Oncol Rep. 2014; 31: 1191-1198.

41. Winograd R, Byrne KT, Evans RA, Odorizzi PM, Meyer AR, Bajor DL, Clendenin C, Stanger BZ, Furth EE, Wherry EJ, Vonderheide RH. Induction of T-cell Immunity Overcomes Complete Resistance to PD-1 and CTLA-4 Blockade and Improves Survival in Pancreatic Carcinoma. Cancer Immunol Res. 2015; 3: 399-411.

42. Bailey P, Chang DK, Nones K, Johns AL, Patch AM, Gingras MC, Miller DK, Christ AN, Bruxner TJ, Quinn MC, Nourse C, Murtaugh LC, Harliwong I, et al. Genomic analyses identify molecular subtypes of pancreatic cancer. Nature. 2016; 531: 47-52.

43. Okudaira K, Hokari R, Tsuzuki Y, Okada Y, Komoto S, Watanabe C, Kurihara C, Kawaguchi A, Nagao S, Azuma M, Yagita H, Miura S. Blockade of B7-H1 or B7-DC induces an anti-tumor effect in a mouse pancreatic cancer model. Int J Oncol. 2009; 35: 741-749.

44. Chakravarti N, Prieto VG. Predictive factors of activity of anti-programmed death-1/programmed death ligand-1 drugs: immunohistochemistry analysis. Transl Lung Cancer Res. 2015; 4: 743-751.

45. Rimm D, Schalper K, Pusztai L. Unvalidated antibodies and misleading results. Breast Cancer Res Treat. 2014; 147: 457-458. 
46. Velcheti V, Schalper KA, Carvajal DE, Anagnostou VK, Syrigos KN, Sznol M, Herbst RS, Gettinger SN, Chen L, Rimm DL. Programmed death ligand-1 expression in nonsmall cell lung cancer. Lab Invest. 2014; 94: 107-116.

47. Gadiot J, Hooijkaas AI, Kaiser AD, van Tinteren H, van Boven H, Blank C. Overall survival and PD-L1 expression in metastasized malignant melanoma. Cancer. 2011; 117: 2192-2201.

48. McLaughlin J, Han G, Schalper KA, Carvajal-Hausdorf D, Pelekanou V, Rehman J, Velcheti V, Herbst R, LoRusso P, Rimm DL. Quantitative Assessment of the Heterogeneity of PD-L1 Expression in Non-Small-Cell Lung Cancer. JAMA Oncol. 2016; 2: 46-54.

49. Ilie M, Hofman V, Dietel M, Soria JC, Hofman P. Assessment of the PD-L1 status by immunohistochemistry: challenges and perspectives for therapeutic strategies in lung cancer patients. Virchows Arch. 2016; 468: 511-525.

50. Bigelow E, Bever $\mathrm{KM}, \mathrm{Xu} \mathrm{H}$, Yager $\mathrm{A}$, Wu A, Taube J, Chen L, Jaffee EM, Anders RA, Zheng L. Immunohistochemical staining of B7-H1 (PD-L1) on paraffin-embedded slides of pancreatic adenocarcinoma tissue. J Vis Exp. 2013.

51. Schalper KA, Velcheti V, Carvajal D, Wimberly H, Brown J, Pusztai L, Rimm DL. In situ tumor PD-L1 mRNA expression is associated with increased TILs and better outcome in breast carcinomas. Clin Cancer Res. 2014; 20: 2773-2782.

52. Ribas A, Tumeh PC. The future of cancer therapy: selecting patients likely to respond to PD1/L1 blockade. Clin Cancer Res. 2014; 20: 4982-4984.

53. Choueiri TK, Fay AP, Gray KP, Callea M, Ho TH, Albiges L, Bellmunt J, Song J, Carvo I, Lampron M, Stanton ML, Hodi FS, McDermott DF, et al. PD-L1 expression in nonclear-cell renal cell carcinoma. Ann Oncol. 2014; 25: 2178-2184.

54. Massi D, Brusa D, Merelli B, Ciano M, Audrito V, Serra S, Buonincontri R, Baroni G, Nassini R, Minocci D, Cattaneo L, Tamborini E, Carobbio A, et al. PD-L1 marks a subset of melanomas with a shorter overall survival and distinct genetic and morphological characteristics. Ann Oncol. 2014; 25: 2433-2442.

55. Thompson RH, Kuntz SM, Leibovich BC, Dong H, Lohse CM, Webster WS, Sengupta S, Frank I, Parker AS, Zincke H, Blute ML, Sebo TJ, Cheville JC, et al. Tumor B7-H1 is associated with poor prognosis in renal cell carcinoma patients with long-term follow-up. Cancer Res. 2006; 66: 3381-3385.

56. Kiyasu J, Miyoshi H, Hirata A, Arakawa F, Ichikawa A, Niino D, Sugita Y, Yufu Y, Choi I, Abe Y, Uike N, Nagafuji K, Okamura T, et al. Expression of programmed cell death ligand 1 is associated with poor overall survival in patients with diffuse large B-cell lymphoma. Blood. 2015; 126: 2193-2201.

57. Kim JR, Moon YJ, Kwon KS, Bae JS, Wagle S, Kim KM,
Park HS, Lee H, Moon WS, Chung MJ, Kang MJ, Jang KY. Tumor infiltrating PD1-positive lymphocytes and the expression of PD-L1 predict poor prognosis of soft tissue sarcomas. PLoS One. 2013; 8: e82870.

58. Geng L, Deng J, Jiang G, Song P, Wang Z, Jiang Z, Zhang M, Zheng S. B7-H1 up-regulated expression in human hepatocellular carcinoma tissue: correlation with tumor interleukin-10 levels. Hepatogastroenterology. 2011; 58: 960-964.

59. Xu XD, Hu J, Wang M, Peng F, Tian R, Guo XJ, Xie Y, Qin RY. Circulating myeloid-derived suppressor cells in patients with pancreatic cancer. Hepatobiliary Pancreat Dis Int. 2016; 15: 99-105.

60. Basso D, Fogar P, Falconi M, Fadi E, Sperti C, Frasson C, Greco E, Tamburrino D, Teolato S, Moz S, Bozzato D, Pelloso M, Padoan A, et al. Pancreatic tumors and immature immunosuppressive myeloid cells in blood and spleen: role of inhibitory co-stimulatory molecules PDL1 and CTLA4. An in vivo and in vitro study. PLoS One. 2013; 8: e54824.

61. Vicari AP, Trinchieri G. Interleukin-10 in viral diseases and cancer: exiting the labyrinth? Immunol Rev. 2004; 202 : 223-236.

62. Erdman SE, Rao VP, Poutahidis T, Ihrig MM, Ge Z, Feng Y, Tomczak M, Rogers AB, Horwitz BH, Fox JG. CD4(+) $\mathrm{CD} 25(+)$ regulatory lymphocytes require interleukin 10 to interrupt colon carcinogenesis in mice. Cancer Res. 2003; 63: 6042-6050.

63. Pfirschke C, Engblom C, Rickelt S, Cortez-Retamozo V, Garris C, Pucci F, Yamazaki T, Poirier-Colame V, Newton A, Redouane Y, Lin YJ, Wojtkiewicz G, Iwamoto Y, et al. Immunogenic Chemotherapy Sensitizes Tumors to Checkpoint Blockade Therapy. Immunity. 2016; 44: 343354.

64. Soares KC, Rucki AA, Wu AA, Olino K, Xiao Q, Chai Y, Wamwea A, Bigelow E, Lutz E, Liu L, Yao S, Anders RA, Laheru D, et al. PD-1/PD-L1 blockade together with vaccine therapy facilitates effector T-cell infiltration into pancreatic tumors. J Immunother. 2015; 38: 1-11.

65. Badea L, Herlea V, Dima SO, Dumitrascu T, Popescu I. Combined gene expression analysis of whole-tissue and microdissected pancreatic ductal adenocarcinoma identifies genes specifically overexpressed in tumor epithelia. Hepatogastroenterology. 2008; 55: 2016-2027.

66. Van den Broeck A, Vankelecom H, Van Eijsden R, Govaere O, Topal B. Molecular markers associated with outcome and metastasis in human pancreatic cancer. J Exp Clin Cancer Res. 2012; 31: 68.

67. Zhang G, Schetter A, He P, Funamizu N, Gaedcke J, Ghadimi BM, Ried T, Hassan R, Yfantis HG, Lee DH, Lacy C, Maitra A, Hanna N, et al. DPEP1 inhibits tumor cell invasiveness, enhances chemosensitivity and predicts clinical outcome in pancreatic ductal adenocarcinoma. PLoS One. 2012; 7: e31507.

68. Lunardi S, Jamieson NB, Lim SY, Griffiths KL, Carvalho- 
Gaspar M, Al-Assar O, Yameen S, Carter RC, McKay CJ, Spoletini G, D’Ugo S, Silva MA, Sansom OJ, et al. IP-10/ CXCL10 induction in human pancreatic cancer stroma influences lymphocytes recruitment and correlates with poor survival. Oncotarget. 2014; 5: 11064-11080. doi: 10.18632/oncotarget.2519.

69. Park M, Kim M, Hwang D, Kim WK, Kim SK, Shin J, Park ES, Kang CM, Paik YK, Kim H. Characterization of gene expression and activated signaling pathways in solidpseudopapillary neoplasm of pancreas. Mod Pathol. 2014; 27: 580-593.

70. Perez-Mancera PA, Rust AG, van der Weyden L, Kristiansen G, Li A, Sarver AL, Silverstein KA, Grutzmann R, Aust D, Rummele P, Knosel T, Herd C, Stemple DL, et al. The deubiquitinase USP9X suppresses pancreatic ductal adenocarcinoma. Nature. 2012; 486: 266-270.

71. Winter C, Kristiansen G, Kersting S, Roy J, Aust D, Knosel T, Rummele P, Jahnke B, Hentrich V, Ruckert F, Niedergethmann M, Weichert W, Bahra M, et al. Google goes cancer: improving outcome prediction for cancer patients by network-based ranking of marker genes. PLoS Comput Biol. 2012; 8: e1002511.

72. Grutzmann R, Pilarsky C, Ammerpohl O, Luttges J, Bohme A, Sipos B, Foerder M, Alldinger I, Jahnke B, Schackert HK, Kalthoff H, Kremer B, Kloppel G, et al. Gene expression profiling of microdissected pancreatic ductal carcinomas using high-density DNA microarrays. Neoplasia. 2004; 6: 611-622.

73. Palmer C, Diehn M, Alizadeh AA, Brown PO. Cell-type specific gene expression profiles of leukocytes in human peripheral blood. BMC Genomics. 2006; 7: 115.

74. Rody A, Holtrich U, Pusztai L, Liedtke C, Gaetje R, Ruckhaeberle E, Solbach C, Hanker L, Ahr A, Metzler D, Engels K, Karn T, Kaufmann M. T-cell metagene predicts a favorable prognosis in estrogen receptor-negative and HER2-positive breast cancers. Breast Cancer Res. 2009; 11: R15.
75. Bertucci F, Finetti P, Cervera N, Charafe-Jauffret E, Mamessier E, Adelaide J, Debono S, Houvenaeghel G, Maraninchi D, Viens P, Charpin C, Jacquemier J, Birnbaum D. Gene expression profiling shows medullary breast cancer is a subgroup of basal breast cancers. Cancer Res. 2006; 66: 4636-4644.

76. Sabatier R, Finetti P, Mamessier E, Raynaud S, Cervera N, Lambaudie E, Jacquemier J, Viens P, Birnbaum D, Bertucci F. Kinome expression profiling and prognosis of basal breast cancers. Mol Cancer. 2011; 10: 86.

77. Teschendorff AE, Miremadi A, Pinder SE, Ellis IO, Caldas C. An immune response gene expression module identifies a good prognosis subtype in estrogen receptor negative breast cancer. Genome Biol. 2007; 8: R157.

78. Gatza ML, Lucas JE, Barry WT, Kim JW, Wang Q, Crawford MD, Datto MB, Kelley M, Mathey-Prevot B, Potti A, Nevins JR. A pathway-based classification of human breast cancer. Proceedings of the National Academy of Sciences of the United States of America. 2010; 107: 6994-6999.

79. Smyth GK. Linear models and empirical bayes methods for assessing differential expression in microarray experiments. Stat Appl Genet Mol Biol. 2004; 3: Article3.

80. Hochberg Y, Benjamini Y. More powerful procedures for multiple significance testing. Stat Med. 1990; 9: 811-818.

81. McShane LM, Altman DG, Sauerbrei W, Taube SE, Gion M, Clark GM. REporting recommendations for tumour MARKer prognostic studies (REMARK). Br J Cancer. 2005; 93: 387-391. 